\title{
Ácidos graxos poliinsaturados e ácido linoléico conjugado na carne suína. Benefícios para a saúde humana: Revisão
}

\author{
Lina Maria Peñuela-Sierra ${ }^{1,2}$, Roman David Castañeda-Serrano ${ }^{1,2}$, R.A. Sanmiguel ${ }^{3}$ \\ ${ }^{I}$ Professor, Programa de Medicina Veterinaria y Zootecnia, Universidad del Tolima, Ibagué-Tolima, Colômbia. \\ ${ }^{2}$ Grupo de Investigación en Sistemas Agroforestales Pecuarios - Universidad del Tolima \\ ${ }^{3}$ Professor Programa de Medicina Veterinaria y Zootecnia, Universidad Cooperativa de Colômbia, Ibagué- \\ Tolima, Colômbia. \\ *Autor para correspondência, E-mail: Impenuelas@ut.edu.co
}

RESUMO. A incorporação de ácidos graxos poliisaturados PUFAs e acido linoléico conjugado CLA, em dietas para suínos é uma pratica nova desenvolvida a partir de pesquisas onde observaram os benefícios que estas substancias fornecem para a saúde humana, com o intuito demelhorar a razão de poliinsaturados:saturados, os nutricionistas têm focado no tipo de PUFA e o equilíbrio na dieta entre n-3 PUFA formado do ácido linolênico (18:3) e n-6 PUFA formado do ácido de linoléico (18:2). A relação de PUFA n-6:n-3 também é um fator de risco em cânceres e doenças coronárias, especialmente a formação de coágulos de sangue que conduzem a um ataque do coração. Outra molécula na qual se tem prestado muita atenção nos últimos anos é o ácido linoléico conjugado (CLA) este, é um nome coletivo que se refere uma mistura de isômeros conjugados do ácido linoléico (cis/trans). O interesse de alimentar suínos com CLA tem aumentado na última década como resultado de seu potencial para aumentar taxa de ganho, melhora conversão alimentar, redução da gordura corporal, aumento na taxa de crescimento de proteína e mais importante ainda os benefícios que o CLA pode trazer para a saúde humana, com comprovados efeitos incluindo a inibição química da carcinogênese em modelos animais, estímulo ao sistema imune, diminuição de efeitos catabólicos, diminuição da aterosclerose e maior crescimento do tecido magro.

Palavras chave:PUFAs, ácidos graxos poliinsaturados, CLA, EPA, DHA, LDL

\section{Long chain polyunsaturated fatty acids and conjugated linoleic acid inpork meat. Health benefits: Review}

\begin{abstract}
The incorporation of fatty acids polyunsaturated PUFAs and conjugated linoleic acid CLA in pig diets is a new practice developed from research which looked at the benefits that these substances provide for human health, with the aim of improving the ratio of polyunsaturated to saturated, nutritionists has focused on the type of PUFA and the balance between dietary n-3 PUFA formed linolenic acid (18: 3) and n-6 PUFA linoleic acid formed (18: 2). The ratio of PUFA $n-6: n-3$ is also a risk factor for cancer and heart disease, especially the formation of blood clots that lead to heart attack. Another molecule in which one has paid much attention in recent years is conjugated linoleic acid (CLA) this is a collective name that refers to a mixture of conjugated isomers (cis / trans) linoleic acid. The interest of feeding pigs with CLA has increased in the last decade as a result of its potential to increase rate of gain, improved feed conversion, reduced body fat, increased rate of growth of protein and more importantly the benefits that CLA can bring to human health, with proven effects including inhibition of chemical carcinogenesis in animal models, stimulating the immune system, decreasing catabolic effects, decreased atherosclerosis and increased lean tissue growth.
\end{abstract}

Keywords: PUFA, CLA, EPA, DHA, LDL, LDL 


\section{Introdução}

O ser humano e os demais mamíferos têm a capacidade de sintetizar ácidos graxos saturados e insaturados, mas são incapazes de sintetizar ácidos graxos específicos, sem os quais os organismos não funcionariam adequadamente. Por essa razão, esses ácidos graxos de importância vital são chamados de essenciais e deve ser incluído na dieta alimentar. Os ácidos graxos essenciais para a alimentação humana são o ácido linoléico (n-6) e o ácido alfa linolênico (n-3). O primeiro está presente em grande quantidade na maioria dos óleos vegetais, como o de milho, enquanto o segundo é encontrado em vegetais de folhas verdes e nos óleos de soja, de canola e, principalmente, no de linhaça (Martino \& Takahashi, 2001). Esses ácidos de cadeias longas e insaturados são importantes devido à sua capacidade de se transformarem em formas biologicamente mais ativas, com funções específicas. Os óleos de muitas espécies de peixes marinhos são ricos em ácido eicosapentaenóico (EPA) e em ácido docosahexaenóico (DHA), as duas formas que apresentam cadeias longas e poliinsaturadas ativas da série n-3 usadas diretamente no processo metabólico. Além do aumento no consumo de peixes ricos em óleo, o consumo de ácidos graxos ômega-3 pode ser aumentado através da ingestão de outros alimentos comuns que possuam níveis aumentados de ácidos graxos poliinsaturados. A composição dos ácidos graxos da gema de ovos e de tecidos musculares de aves e suínos pode ser modificada para melhor condizer com as recomendações. A inclusão de ácidos graxos poliinsaturados em produtos de origem animal (carne, ovos e leite), agregando valor a estes produtos, seja através da modificação da alimentação dos animais ou da adição durante o processamento industrial, tem sido muito propagada nos últimos anos.

Stewart et al. (2001) verificaram que o consumo de carne suína contendo alto teor de ácidos graxos poliinsaturados por mulheres resultou na diminuição do colesterol total e LDL plasmáticos, além disso, promoveu o aumento de ácidos graxos poliinsaturados e a redução de ácidos graxos saturados e monoinsaturados no plasma e eritrócitos.

Resultados de alguns estudos têm mostrado efeitos benéficos e específicos à saúde humana em decorrência do consumo de ácidos graxos poliinsaturados ômega-3, em particular os ácidos graxos eicosapentaenóico (EPA) e decoeicohexanóico (DHA) que possuem um importante papel metabólico. Como resultado dessas observações, recentes recomendações relativas ao consumo de lipídeos têm dado ênfase à importância de se consumirem níveis mais altos desses ácidos graxos.

Além dos PUFAs outra molécula na qual se tem prestado muita atenção nos últimos anos é o ácido linoléico conjugado (CLA) este, é um nome coletivo que se refere uma mistura de isômeros conjugados do ácido linoléico (cis/trans). O interesse de alimentar suínos com CLA tem aumentado na última década como resultado de seu potencial para aumentar taxa de ganho, melhora conversão alimentar, assim como também reduz a gordura corporal e aumenta a taxa de crescimento de proteína (Ostrowska et al., 1999).

Embora a carne de suínos contenha menor concentração de ácidos graxos poliinsaturados que os peixes marinhos, esta constitui uma fonte importante de ômega-3 e ômega-6 para a maioria da população, visto que o consumo de tais peixes é proporcionalmente mais baixo. A possibilidade de aumentar os níveis destes ácidos graxos poliinsaturados e CLA na carne suína ajuda a combater a imagem negativa desta, atribuída à quantidade de gordura saturada, que na verdade não é alta (Scollan et al., 2001).

\section{Composição da carne suína}

A composição geral de carne suína consiste de $72 \%$ de água, $20 \%$ de proteína, $7 \%$ de gordura, $1 \%$ de minerais e menos que $1 \%$ de carboidratos. Comparando-se com outros alimentos, a carne suína é um alimento rico em proteína, e pobre em carboidratos e contém relativamente baixo nível energético (em torno de $147 \mathrm{kcal} / 100 \mathrm{~g}$ de carne suína). Além disso, a carne suína é uma das fontes mais importantes de vitamina B1, contendo também como vitaminas principais, B2, B6, B12, A e C. A carne suína, no entanto, é considerado um alimento de alto teor de colesterol (Bragagnolo et al., 2002).

Os valores encontrados na literatura para colesterol em carne suína variam grandemente. Estas discrepâncias podem ser atribuídas à variação natural das amostras devido a fatores como tipo de corte, idade, raça e dieta do animal, mas também, pelo menos em parte, à análise propriamente dita. Apesar de existir uma ampla literatura internacional sobre lipídios totais, 
colesterol e composição de ácidos graxos, dados brasileiros são escassos, embora as doenças cardiovasculares sejam as maiores causas de morte no país (Bragagnolo et al., 2002).

A qualidade tecnológica e organoléptica da carne fresca e de produtos de carne suína é determinada pela fração de lipídios. A influencia da composição de ácidos graxos da gordura intramuscular de suínos ibéricos foi observada por Ruiz et al. (2000) e Cava et al. (1999) onde concluíram que a composição lipidica afetava o sabor da carne, e que a variabilidade genética das linhas ibéricas influenciava as características produtivas.

Vários autores descreveram diferenças nos parâmetros de crescimento e composição corporal das linhas ibéricas, como ganho de peso diário, peso de lombo, comprimento de carcaça e carcaça (Rodríguez et al., 1993). Tejeda et al. (2002) e Petron (2002) acharam pequenas diferenças no conteúdo de gordura intramuscular e composição lipídica da carne fresca e seca de três raças ibéricas.

Entretanto, Estévez et al. (2003) acharam um alto conteúdo de gordura intramuscular e baixo conteúdo de ácido linoléico (C18:2 n 6) em animais da linha Lampiño (raça ibérica). Níveis altos de gordura intramuscular foram associados com melhoras na qualidade da carne consumida (Wood et al., 2004).

O maior desafio é produzir carne com um mínimo de gordura visível que satisfaça o consumidor. A maioria dos procedimentos consiste em manipular o conteúdo de gordura e sua composição através de uma alimentação estratégica, que possa mudar vários aspectos da qualidade da carne entre eles o total de gordura e a composição dos ácidos graxos.

Teores de lipídios totais e ácidos graxos saturados e insaturados na carne suína

Geralmente, as carnes são constituídas por 60 a $80 \%$ de água e 15 a $25 \%$ de proteína, sendo o restante formado principalmente por gorduras, sais, pigmentos e vitaminas.

Carnes são alimentos preferidos pela maioria dos consumidores, no entanto, são apontados como alimentos com alto teor de colesterol, gordura e ácidos graxos saturados e baixos níveis de ácidos graxos insaturados, principalmente a carne suína.

A doença cardiovascular é a principal causa de morte no Brasil e em muitos países. A incidência desta doença tem sido relacionada com os altos níveis de colesterol sanguíneo (Keys, 1970, Mattson et al., 1972, Kato et al., 1979).

Para mantê-lo em baixos níveis a American Heart Association (2007) recomenda uma dieta equilibrada, com baixo teor de lipídios, colesterol e ácidos graxos saturados e maior taxa de ácidos graxos monoinsaturados e poliinsaturados.

Os ácidos graxos saturados são considerados hipercolesterolêmicos e os mais preocupantes, neste sentido, são mirístico (C14:0), láurico (C12:0) e palmítico (C16:0). O ácido esteárico (C18:0) tem função neutra, uma vez que no organismo se transforma imediatamente em ácido oléico (C18:1) (Sinclair, 1993).

Tabela 1. Percentagem de ácidos graxos saturados, monoinsaturados e poliinsaturados em carnes

\begin{tabular}{lccc}
\hline Ácidos graxos (\%) & Carne bovina & Carne suína & Carne de frango \\
\hline Saturados & $45 \pm 4$ & $40 \pm 2$ & $33 \pm 1$ \\
Monoinsaturados & $40 \pm 41$ & $44 \pm 2$ & $46 \pm 2$ \\
Poliinsaturados & $7 \pm 4$ & $14 \pm 2$ & $21 \pm 1$ \\
\hline
\end{tabular}

Fonte: Bragagnolo (2001)

Os ácidos graxos saturados aumentam o nível de colesterol sanguíneo por reduzirem a atividade do receptor LDL-colesterol e reduzirem o espaço livre de LDL na corrente sanguínea (Grundy e Denke, 1990). Dos ácidos graxos insaturados, merecem atenção os ácidos graxos trans oriundos do processamento e da hidrogenação dos óleos e gorduras. São considerados mais aterogênicos que os saturados, pois além de aumentarem o nível de LDL, diminuem o nível de HDL. Já os ácidos graxos poliinsaturados naturalmente cissão benéficos uma vez reduzem agregações das plaquetas e os triacilgliceróis e, 
consequentemente, o risco de doenças cardíacas (Kinsella et al., 1990).

A composição de ácidos graxos na carne suína, média dos quatro cortes analisados (paleta, pernil, lombo e toucinho) foi, $40 \pm 2,44 \pm 2$ e 14 $\pm 2 \%$ para ácidos graxos saturados, monoinsaturados e poliinsaturados, respectivamente (Tabela 1). Na carne bovina, média dos três cortes analisados, foi de $45 \pm 4,40$ \pm 4 e $7 \pm 4 \%$ para ácidos graxos saturados, monoinsaturados e poliinsaturados, respectivamente. Na carne de frango os valores médios considerando carne branca, carne escura e pele foram de $33 \pm 1,46 \pm 2$ e $21 \pm 1 \%$ para saturados, monoinsaturados e poliinsaturados, respectivamente (Bragagnolo, 2001).

Comparando-se as três carnes, observa-se que a carne bovina apresentou maior teor de ácidos graxos saturados e menor teor de ácidos graxos poliinsaturados enquanto o frango mostrou ter mais ácidos graxos poliinsaturados e menos ácidos graxos saturados que as demais. Em termos de ácidos graxos monoinsaturados as três carnes foram semelhantes (Grundy, 1994).

Atualmente é importante considerar a relação $\omega 6 / \omega 3$ dos ácidos graxos. Na carne bovina a razão foi 1,9 (Tabela 2) estando dentro do máximo recomendado pelo British Departmentof Health da Inglaterra em 1994. A razão $\omega 6 / \omega 3$ para carne suína e de frango variou de 10 a 21 , estando bem acima do máximo recomendado de 4 para a dieta total (Wood et al., 2003), implicando a necessidade de compensar esta deficiência com outros componentes da dieta.

Tabela 2. Percentagem de ácidos graxos saturados, monoinsaturados e poliinsaturados em carnes

\begin{tabular}{lccccc}
\hline \multirow{2}{*}{ Analito } & Carne bovina & \multicolumn{2}{c}{ Carne suína } & \multicolumn{2}{c}{ Carne de frango } \\
& Contrafilé & Lombo & Pernil & Branca & Escura \\
\hline Lipídios totais $(\mathrm{g} / 100 \mathrm{~g})$ & 2,4 & 3,0 & 5,0 & 2,7 & 7,0 \\
Saturados $(\mathrm{g} / 100 \mathrm{~g})$ & 0,98 & 1,09 & 1,82 & 0,84 & 2,18 \\
Monoinsaturados $(\mathrm{g} / 100 \mathrm{~g})$ & 0,88 & 1,20 & 2,00 & 1,17 & 3,04 \\
Poliinsaturados $(\mathrm{g} / 100 \mathrm{~g})$ & 0,15 & 0,38 & 0,64 & 0,54 & 1,39 \\
$\omega-3 / \omega-6$ & 1,9 & 21 & 12 & 14 & 10 \\
\hline
\end{tabular}

Fonte: Bragagnolo (2001)

\section{Ácidos graxos Poliinsaturados}

Enquanto o corpo humano tem capacidade de sintetizar por si mesmo o colesterol e ácidos graxos saturados e monoinsaturados, é incapaz de sintetizar os ácidos graxos poliinsaturados, tais como os ácidos linoléico (C18:2) e alfalinolênico (C18:3) (Brenner, 1987).

Estes ácidos graxos poliinsaturados são, no entanto, essenciais à vida e, portanto, necessitam ser introduzidas no organismo via dieta. Ácidos graxos essenciais são aqueles que contrariamente a todos os outros não podem ser produzidos pelo ser humano em seu organismo através de metabolismo próprio.

A ausência destes ácidos graxos na dieta causa sintomas de carência muito graves. Os primeiros sinais aparecem em forma de distúrbios cutâneos que atestam sérios distúrbios na economia de água do organismo e afetam gravemente o fígado e os rins. Os seres de pouca idade são especialmente sujeitos à falta de ácidos graxos essenciais.

Os ácidos graxos essenciais, ácidos linoléico e alfa-linolênico são sintetizados unicamente pelos vegetais e têm uma dupla ligação na posição $\omega-6$ (ômega-6) ou $\omega-3$ (ômega-3), numerados os carbonos a partir do agrupamento metil terminal (Figura 1).

Os ácidos graxos poliinsaturados podem ser considerados de acordo com as famílias onde a estrutura terminal é a mesma. Por esta razão, as posições das duplas ligações, ao longo da cadeia carbônica, pode ser designada pela letra grega ômega $(\omega)$, e um número que se refere ao número de átomos de carbono separando o agrupamento metila terminal da dupla ligação. Existem assim duas famílias de poliinsaturados essenciais: $\omega-6$ (ômega-6) derivada do ácido linoléico (C18:2 $\omega$ - 
6) e a $\omega-3$ (ômega-3) derivada do ácido alfalinolênico (C18:3 $\omega-3)$ (Tabela 3).

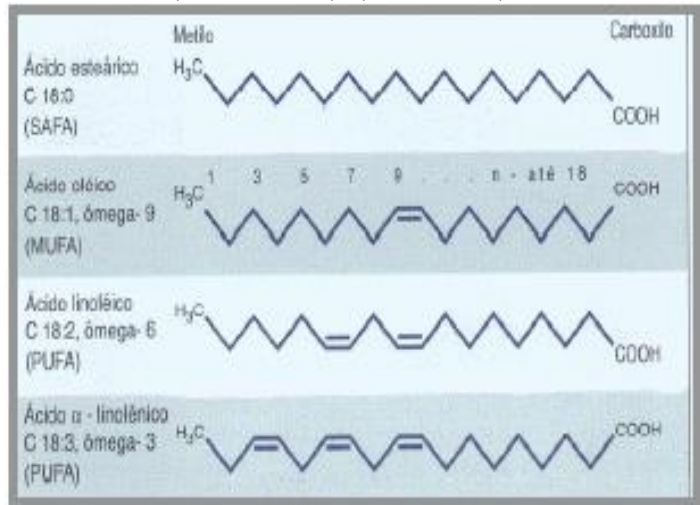

Figura 1. Ácidos graxos essenciais - ácidos linoléico e alfa-linolênico (Castro, 2006).

Os ácidos linoléico e alfa-linolênico quando ingeridos, sofrem uma reação de insaturação e uma reação de elongação de cadeia de carbono, através de enzimas específicas e são convertidos em ácidos graxos poliinsaturados de cadeia mais longa, sendo estes precursores de uma gama variável de substâncias, como por exemplo, os hormônios, que desempenham atividades importantes a nível fisiológico.

\section{CLA}

O ácido linoléico conjugado (CLA) é um termo usado para designar uma mistura de isômeros posicionais e geométricos do ácido linoléico (C18:2) insaturados por duas duplas ligações conjugadas, ou seja, separadas por uma simples ligação carbono-carbono. Os dois isômeros que apresentam concentrações predominantes em preparados biologicamente ativos são o cis-9 trans-11 e o trans-10 cis-12, ocorrendo na maioria dos casos maior proporção cis-9 trans-11 que de o trans-10 cis-12.

Tabela 3. Ácidos graxos Poliinsaturados Arranjados por Família

\begin{tabular}{lllc}
\hline Família & Nome sistemático & Abreviatura & Nome trivial \\
\hline & $9,12,15$-Octadecatrienóico & $\mathrm{C} 18: 3 \omega 3$ & $\alpha$-Linolênico \\
& $6,9,12,15$-Octadecatetraenóico & $\mathrm{C} 18: 4 \omega 3$ & Estearidônico \\
& $5,8,14,17$ - Eiocosapentaenóico & $\mathrm{C} 20: 5 \omega 3$ & \\
& $4,7,10,13,16,19-$-Docosahexaenóico & $\mathrm{C} 22: 6 \omega 3$ & \\
\hline & $9,12,15-$ Octadecadienóico & $\mathrm{C} 18: 2 \omega 6$ & Linolênico \\
& $6,12,15$-Octadecatrienóico & $\mathrm{C} 18: 3 \omega 6$ & $\gamma$-Linolênico \\
& $5,8,11,14$-Eicosatetraenóico & $\mathrm{C} 20: 4 \omega 6$ & Araquidônico \\
& $7,10,13,16$-Docosatetraenóico & $\mathrm{C} 22: 4 \omega 6$ & \\
\hline
\end{tabular}

Fonte: Pedroso (2001)

Dugan et al. (1997) observaram que suínos alimentados com 2\% CLA depositaram menos gordura subcutânea $(6.8 \%)$ e a carcaça foi mais magra $(+2.3 \%)$ que suínos alimentados com $2 \%$ de óleo de girassol. Tischendorf et al. (2002) concluiram que $0.5 \%$ de inclusão de CLA não era suficiente para influenciar as respostas de qualidade da carne, quando comparada com $0.5 \%$ de óleo de girassol. Porém, em outro estudo a porcentagem de carne magra aumentou com adição de $0.5 \%$ e $1 \%$ CLA (Mathiesen, 2003). Ao usar 5\% CLA na dieta, Joo et al. (2002) observaram um aumento da gordura intramuscular quando comparado com o grupo controle, ou grupos alimentados com $1 \%$ ou
2.5\% CLA, mas nenhum nível de CLA afetou o $\mathrm{pH}$ da carne.

Suínos alimentados com CLA diminuíram a porcentagem de colesterol intramuscular segundo Joo et al. (2002). Igualmente, ocorreu uma redução da concentração de colesterol total e HDL, assim como aumentou a concentração de ácidos graxos livres no protoplasma.

Os resultados do perfil de lipídios do protoplasma podem indicar um metabolismo de lipídio alterado nos suínos alimentados com CLA quando comparados com o controle. O aumento dos ácidos graxos livres no protoplasma de suínos alimentados com CLA pode indicar uma mobilização mais alta de ácidos graxos dos 
tecidos quando comparados com suínos alimentados com óleo de girassol.

\section{Fontes de CLA para a carne suína}

$\mathrm{Na}$ atualidade existem varias formas e apresentações de CLA que em sua maioria são sintéticos. Para a produção do CLA precisa-se de um processo industrial é necessária a utilização de um óleo rico em ácido linoléico ( $99, \mathrm{c} 12$ C18:2) e implica a incorporação ácidosheterogêneos de moderada concentração em médio alcalino em presença de metais que atuam como agentes catalíticos. A reação pode começar quase com a mesma probabilidade, no carbono 9 ou no 12 , caso se produza o deslocamento da dupla ligação localizada no carbono 9 no sentido da posição 10 , obtendo-se simultaneamente a conversão da configuração cis á trans, que resulta mais estável. O produto, mais originado é o t10,c12 CLA, embora também podem produzir-se pequenas quantidades de outros isômeros. Se a reação começa no carbono 12 a dupla ligação se desloca à posição 11 , dando lugar a um isômero c9,t11 CLA e pequenas quantidades de outros compostos.

\section{Fontes de PUFA ( $\omega$-3) para a carne suína}

\section{Linhaça (Lnunus itatissimum L.)}

Com relação às sementes oleaginosas, a semente de linhaça ou seu óleo têm sido muito pesquisados (Warnants et al., 2001). A semente de linhaça é rica em ácido alfa linolênico (C18:3 n-3), nos suínos, esse ácido é dessaturado, alongado e preferencialmente convertido a ácido eicosapentaenóico (EPA) (Riley et al., 2000). A semente integral de linhaça tem ainda uma vantagem adicional em relação ao seu óleo pelo fato de apresentar uma substância antioxidante natural e a casca, que protege o óleo de danos oxidadativos (Warnants et al., 2001).

Matthews et al. (2000) utilizaram semente integral de linhaça em três níveis diferentes $(0$, $50,100 \mathrm{~g} / \mathrm{kg}$ ) nas dietas de suínos na fase de terminação. Os autores observaram que os níveis de ácido alfa-linolênico foram aumentados em todos os tecidos estudados de acordo com o aumento dos níveis de linhaça na dieta. No plasma, músculo longissimustorácico, fígado e rins, a concentração de EPA aumentou, sendo que altos níveis de DHA foram encontrados no plasma. Houve mudanças marcantes nas relações n-6:n-3 e na relação entre os ácidos araquidônico (n-6) e eicosapentanóico (EPA, n-3). Os resultados deste estudo possibilitaram, ainda, concluir que adição de semente de linhaça integral nas dietas de suínos em terminação, em níveis de até $100 \mathrm{~g} / \mathrm{Kg}(10 \%)$, não tem efeito negativo sobre as qualidades da carcaça e da carne, além de proporcionar níveis elevados de ácidos graxos n-3 nesta última.

Entretanto Sheard et al. (2000) mostraram que a razão $\omega-6: \omega-3$ em suínos poderia reduzir ao nível recomendado (menos do que 4) ao consumirem linhaça inteira esmagada, sem detectar efeitos adversos na qualidade da carne. Eles mostraram que aumentando o conteúdo de ácido linolênico (C18: 3) no lipídios totais do músculo Longissimus de $1 \%$ do controle para $1,6 \%$ nos que consumiram linhaça, abaixou a razão $\omega-6: \omega-3$ para cinco se comparado com nove nos controles. Não teve efeitos nas mensurações quanto a oxidação de lipídeos usando teste com substâncias reativas a ácido tiobarbitúrico (TBARSs), saturação da cor ou na qualidade de costeletas de lombo grelhadas.

\section{Canola (Brassicanapus e Brassica campestris)}

O óleo extraído da semente de canola contém menor teor de gordura saturada, com apenas 7\%, contra $12 \%$ do girassol, e ainda apresenta o teor mais elevado (11\%) de ácido alfa-linoléico (um ácido graxo Ômega-3).

Busbomm et al. (1991) estudaram a influencia da forma da canola (intacta $-20 \%$ ou moída $20 \%$ ) sobre o perfil de ácidos graxos nos tecidos adiposos perirenal (AP) e subcutâneo (AS) e músculos Longissimus (ML) de suínos em terminação por 8 semanas, comparado a dieta controle (contendo farelo de soja). Suínos alimentados com canola tiveram melhor $(\mathrm{P}<0,05)$ proporções de ácidos graxos mono e poliinsaturados e menos $(\mathrm{P}<0,05)$ ácidos graxos saturados em AP e AS, sendo as diferenças mais pronunciadas para AP do que AS. No ML, suínos alimentados com canola tenderam a ter elevado níveis de ácidos graxos insaturados e menos saturados, mas somente para ácido linolênico foi significativo. Concluindo assim, a alimentação com canola aumenta o grau de instauração do AP e AS, mas com menor efeito no ML e tecido adiposo intramuscular.

Myers et al. (1992) trabalharam com dietas de 0,5 ou $10 \%$ de óleo de canola para verificar a influencia destas dietas sobre a composição de ácidos graxos da gordura da carcaça de suínos em fase de crescimento-terminação. A adição de óleo 
de canola nos níveis 5 e 10\%, respectivamente, resultou em uma redução de 23 e $37 \%(\mathrm{P}<0,01)$ em ácidos graxos saturados, aumento de 3 e $8 \%$ $(\mathrm{P}<0,01)$ em ácidos graxos monoinsaturados, e de 37 e $77 \% \quad(\mathrm{P}<0,01) \quad$ em ácidos graxos poliinsaturados na gordura da carcaça se comparados com as carcaças que receberam as dietas sem óleo de canola. Assim, a adição de óleo de canola nas dietas de suínos na fase de crescimento-terminação tem uma favorável influência no aumento da razão insaturados:saturados na gordura da carcaça suína.

Sandstrom et al. (2000) incorporaram óleo de colza (6\%) com ou sem a suplementação de $200 \mathrm{mg} / \mathrm{kg}$ de vitamina $\mathrm{E}$ na ração de suínos dos 25 aos $100 \mathrm{~kg}$, posteriormente, forneceram a carne desses animais a humanos saudáveis do sexo masculino por três semanas. Desta forma, verificaram que a adição do óleo de colza na dieta dos animais reduziu a relação entre os ácidos graxos saturados e poliinsaturados da gordura suína, porém não encontraram diferenças nos níveis de colesterol em VLDL, LDL e HDL, bem como nos níveis de triglicérides totais ou em VLDL dos indivíduos tratados.

\section{Benefícios para a saúde humana dos PUFAs e do CLA}

\section{Benefícios e efeitos medicinais dos PUFAs}

Os eicosanóides são profundamente ativos fisiologicamente em concentrações extremamente baixas e estão envolvidos nas funções dos sistemas cardiovascular, nervoso e imunológico, além de afetar as funções das glândulas endócrina e exócrina. Existem evidências do efeito seletivo de PUFAs $n-3$, indicando uma baixa incidência de doenças isquêmicas do coração, medidas em pesquisas aplicadas aos esquimós da Groenlândia, consumidores de uma dieta rica em frutos do mar (média de $400 \mathrm{~g}$ de peixe/dia), quando comparados aos esquimós residentes na Dinamarca, que consomem quantidades limitadas de peixes (Jorgensen \& Dyerberg, 1983).

Os humanos e os animais carnívoros, podem converter o ácido linoléico (LA, ômega-6) em ácido araquidônico (AA, C20 : 4, $\omega 6$ ), e o ácido alfa-linolênico (LNA, ômega-3) em ácido eicosapentaenóico (EPA, C20 : 5, 13 ), ácido docosaenóico (DHA, C $22: 6, \omega 3$ ) (Figura 5) e ácido docosapentaenóico (DPA, C22 : 5, 63 ) (Figura 5). Ainda que seja reconhecida a competição entre as famílias $\omega-6$ e $\omega$-3 pelas mesmas enzimas de desaturação (delta-6 saturase), estas preferem os ácidos ômegas- $3 \mathrm{em}$ relação aos ácidos ômega-6 (Fagundes, 2002).

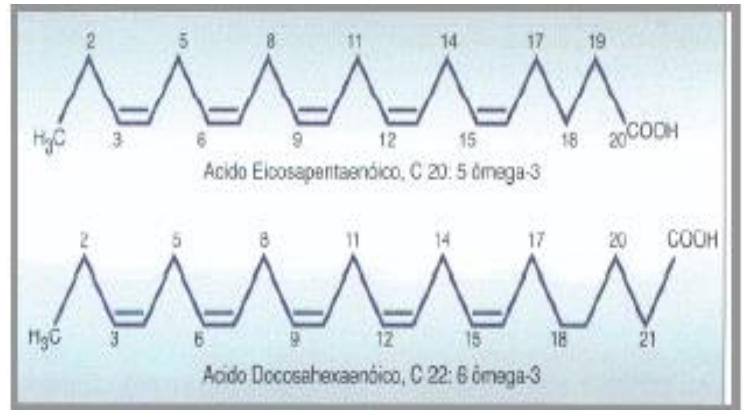

Figura 2. Ácidos graxos EPA e DHA (Castro, 2006)

As duas classes de PUFA devem ser muito bem diferenciadas pois são metabolicamente diferentes e possuem funções fisiológicas opostas, deste modo o equilíbrio nutricional é importante para se conseguir a homeostase e desenvolvimento normal do organismo. Um balanço da proporção de $\omega-6 / \omega-3$ na dieta é essencial no metabolismo do organismo humano, levando a prevenção de doenças cardiovasculares e crônicas degenerativas e também a uma melhor saúde mental (Simopoulos, 1999a).

O LA e o AA têm um papel importante na integridade da hipófise e no transporte das vitaminas lipossolúveis. O AA é abundante no tecido nervoso, entretanto a família ômega-6 produz eicosanóides inflamatórios e cancerígenos, aumentando o risco de situações como: câncer, morte súbita, doenças cardíacas, vasoconstrição, aumento da pressão arterial, elevação da taxa de triglicerídeos, artrite, depressão entre outras doenças inflamatórias. $\mathrm{O}$ excesso de LA e de AA podem resultar no aumento dos níveis de tromboxano causando efeitos indesejáveis no metabolismo animal.

Os ácidos graxos ômega-3 são antiinflamatórios, antitrombóticos, antiarrítmicos e reduzem os lipídeos do sangue, tendo propriedades vasodilatadoras. Esses efeitos benéficos foram demonstrados na prevenção de doenças cardíacas, da hipertensão, do diabete tipo 2 , da artrite reumatóide entre outras (Fagundes, 2002).

A série $\omega-3$ predomina nos fosfolipídios das membranas celulares, dos quais dependem sua permeabilidade e flexibilidade. O DHA é encontrado de forma particularmente concentrada no cérebro, retina, testículos e esperma. O EPA promove a prevenção da agregação plaquetária, o 
retardo no tempo de coagulação do sangue e a diminuição da pressão sanguínea. As duas séries modulam o metabolismo e o transporte do colesterol, formando parte das lipoproteínas a ele associadas. Os $\omega-3$ são mais eficazes e mais ativos que os $\omega-6$ e estes, mais eficazes que os monoinsaturados (MUFAs).

De acordo com vários estudos, as doenças degenerativas como diabete, artrite e o câncer, estão relacionadas em parte à desproporção atual da concentração dos ácidos ômega-6 e ômega-3 que constituem nossa alimentação, ou seja, uma grande concentração de ômega-6 e uma escassez de ômega-3 (Fagundes, 2002). Assim, segundo Simopoulos et al. (1999b), é consenso científico de que é necessário reduzir a quantidade de ácidos graxos poliinsaturados ômega- 6 das dietas e aumentar a concentração de ácidos ômega-3. A afirmação tem como ponto central de embasamento, a justificativa de que, nas dietas do mundo ocidental, são utilizados de forma excessiva óleos vegetais ricos em ômega-6, que se originam do processamento industrial de hidrogenação. Este tipo de processamento é verificado intensamente na atualidade e objetiva fazer com que os óleos vegetais tornem-se mais estáveis e menos susceptíveis a rancificação, apresentando, portanto, um maior tempo de vida útil de "prateleira".

Segundo Fagundes (2002), este desequilíbrio entre essas duas famílias de ácidos é "apenas parte do problema" relativo à doenças degenerativas. Ainda mais difícil é a previsão sobre os resultados finais deste desequilíbrio sobre a composição da gordura, uma vez que estes ácidos competem em humanos pela mesma enzima para desaturação (delta-6 dessaturase), assim como, seus principais derivados (AA e EPA) também apresentam concorrência por um único sítio para sua dessaturação realizada pela enzima delta-5 dessaturase.

Desta maneira, um excesso na ingestão de ácidos graxos ômega 6 pode resultar em um problema de desequilíbrio dos respectivos ácidos graxos poliinsaturados ômega 3. Atualmente, o estudo do balanço $\omega-6 / \omega-3$ está sendo muito discutido. Mais pesquisas são necessárias para elucidar essas interações.

Um excesso de ácido linoléico vai impedir a transformação do $\omega$-linolênico em seus derivados EPA e DHA, o mesmo acontecerá no caso contrário, com um menor consumo do ácido linoléico haverá uma diminuição da formação do ácido araquidônico.

A concorrência entre os ácidos linoléico e $\omega$ linolênico está determinada pela afinidade da enzima delta 6 dessaturase por ambos ácidos graxos. Como a enzima tem maior especificidade pelos ácidos graxos ômega 3, precisará de menores quantidades destes ácidos que dos ômega 6 para produzir a mesma quantidade de produto (Madsem et al., 1999). Isto significa que deve existir uma proporção maior de ácido linoléico que de $\omega$-linolênico. Portanto, é necessário um equilíbrio entre o aporte dos dois ácidos graxos através da dieta.

O ácido graxo ômega 3 pode ser convertido em um outro tipo de ácido graxo ômega 3, mas um ácido graxo ômega 3 não pode ser convertido em um ácido graxo ômega 6. Por outro lado, o ácido graxo ômega 6 também não pode ser transformado em ácido graxo ômega 3. Porém, a presença do ácido graxo ômega 3 no organismo influencia a concentração de derivados de ácido graxo ômega 6 , e vice-versa. Por exemplo, o ácido araquidônico, derivado de ácido linoléico $\mathrm{n}-6$, encontrado nos lipídios das membranas tem sua formação diminuída com o consumo de EPA, derivado do ácido $\alpha$-linolênico n-3, assim como a capacidade de síntese do DHA pelo organismo humano pode ser inibida pela alta ingestão do ácido linoléico n-6. Então, deve-se equilibrar a proporção de n-3 e n-6 consumidos (Tuley, 1995).

Os óleos marinhos obtidos de peixes e moluscos têm um alto conteúdo de ácidos graxos poliinsaturados $\omega-3$ e pouca quantidade de seus precursores de 18 átomos de carbono, ácidos linoléico e alfa-linolênico.

Embora, o volume de literatura associados com a significância biológica dos ácidos graxos poliinsaturados no laboratório animal é imensa, relativamente poucos estudos tem focado a essencialidade de $\mathrm{C} 18: 2 \omega-6$ e $\mathrm{C} 18: 3 \omega-3$ com relação aos humanos. $\mathrm{Na}$ realidade, os tecidos críticos relacionados às funções fisiológicas dos ácidos graxos poliinsaturados e requisitos nos humanos ainda estão sendo investigados.

No entanto, é recomendado que a ingestão de óleos e gordura contendo ácidos graxos poliinsaturados seja acompanhada de vitamina $\mathrm{E}$ para auxiliar a prevenir a peroxidação lipídica.

Benefícios e efeitos do CLA sobre a saúde humana 
Várias pesquisas têm demonstrado inúmeros efeitos do CLA na saúde humana, onde se tem observado efeitos fisiológicos, incluindo a inibição química da carcinogênese em modelos animais, estímulo ao sistema imune enquanto diminui seus efeitos catabólicos em aves e roedores, diminuição da aterosclerose em coelhos e hamsters, e maior crescimento em ratos (Pariza et al., 2001).

Talvez o fato da descoberta de que o CLA possuía efeitos anticarcinogênicos foi o ponto mais importante para a realização das pesquisas na introdução de CLA em produtos animais, tal descoberta teve início em 1979, com a observação de Pariza et al. (1997) de moduladores de mutagênese em extratos de carne bovina moída grelhada e crua. Posteriormente, demonstrou-se que frações purificadas destes moduladores inibiam o crescimento tumoral em vários ensaios com animais (Ip et al., 1994).

Dentre as várias propriedades do CLA a redução na deposição de gordura corporal é observada em várias espécies de mamíferos e em frangos, sendo o isômero trans 10 cis 12 o mais responsável (Park et al., 1997).

Diversos mecanismos foram observados na redução de gordura corporal mediada pela ação do CLA (diminuição na síntese de lipídios pelos adipócitos, ação sobre a atividade da lipoproteína lipase, aumento do apoptose de adipócitos, etc.), no entanto, até o momento, o mecanismo primário responsável por este processo ainda não foi estabelecido (Mersmann, 2002).

Os Efeitos do CLA na diminuição da aterosclerose também são observados. Mcguire \& Mcguire (1999), citam que 0,5g de CLA por dia causou redução na circulação do colesterol de baixa densidade e de triglicerídeos, em coelhos. $O$ exame da aorta demonstrou que o desenvolvimento de aterosclerose foi reduzido. O CLA também demonstrou efeitos antidiabéticos, melhorias na resposta imune e influencias sobre a formação e reabsorção óssea em ratos. No entanto, estas características ainda não foram comprovadas em humanos (Mcguire \& Mcguire, 1999).

\section{Conclusões}

Atualmente, os alimentos funcionais estão associados à mudança do estilo de vida e a hábitos alimentares mais saudáveis. Os ácidos graxos n-3, n-6 e o CLA encontrados principalmente em peixes e em óleos vegetais e no caso do CLA produtos de ruminantes, são recomendados para a prevenção de doenças cardiovasculares, diminuindo o colesterol e a pressão arterial, além de estarem relacionados com desenvolvimento cerebral e visual. $\mathrm{O}$ consumo de carne suína contendo estas substâncias será no futuro uma alternativa tanto para produtores como para consumidores.

\section{Referências bibliográficas}

American Heart Association. 2007. Dietary Guidelines for Health American Adults. (http://www.americanheart.erg/Heart_and_Str oke_A_Z_Guide/dietg.html).

Bragagnolo, N. 2001. Aspectos Comparativos Entre Carnes Segundo A Composição De Ácidos Graxos E Teor De Colesterol. In: Conferência Internacional Virtual sobre Qualidade de Carne Suína, 2., 2001, Concórdia. Anais... Concórdia: CNPSA

Bragagnolo N. \& Rodriguez-Amaya D.B. 2002. Teores de colesterol, lipídios totais e ácidos graxos em cortes de carne suína. Ciência $e$ Tecnologia de Alimentos, 22, 98-104.

Brenner, R. R. 1987. Biosynthesis and interconversion of essential fatty acids. In: A. L. Willis. Handbook of eicosanoids: prostaglandins and related lipids, v. 1, Chemical and biochemical aspects, part A, Florida (USA): CRC Press. p. 99-117.

Busboom, J.R. et al. 1991. Growth, carcass characteristics, and lipid composition of adipose tissue and muscle of pigs fed canola. Journal ofAnimalScience, 69, 1101-1108.

Cava, R., Ruiz, J., Ventanas, J. et al. 1999. Effect of alpha-tocopheryl acetate supplementation and extensive feeding of the pigs on the evolution of volatile aldehydes during the processing of Iberian ham. Food Science and Technology International, v. 5, p. 235-241.

Castro, I.A. 2006. Desenvolvimento de alimentos funcionais. http://people.ufpr.br/ erscta8/ Funcionais.pdf.

Dugan, M.E.R., Aalhus, J.L., Schaefer, A.L. \& Kramer, J.K.G. 1997. The effect of conjugated linoleic acid on fat to lean repartitioning and feed conversion in pigs. Canadian Journal of Animal Science, 77, 723725.

Estévez, M., Morcuende, D. \& Cava, R. 2003. Physico-chemical characteristics of $\mathrm{M}$. 
Longissimus dorsifrom three lines of freerange reared Iberian pigs slaughtered at $90 \mathrm{~kg}$ live-weight and commercial pigs: A comparative study. Meat Science, 65, 11391146.

Fagundes, L. A. Ômega-3 \& Ômega-6: o equilíbrio dos ácidos gordurosos essenciais na prevenção de doenças. Porto Alegre: Fundação de Radioterapia do Rio Grande do Sul, 2002. 111 p.

Grundy, S.M. \& Denke, M.A. Dietary influences on serum lipids and lipoproteins. Journal Lipid Research,. 31, 1149, 1990.

Grundy, S.M. Influence of stearic acid on cholesterol metabolism relative to other long chain fatty acids. American Journal Nutrition, 60, 986S, 1994.

Ip, C., Scimeca, J.A. \& Thompson, H.J. 1994. Conjugated linoleic acid - A powerful anticarcinogen from animal fat sources. CancerResearch, 74, 1051-1054.

Joo, S. T., Lee, J. I., Ha, Y. L., et al. 2002. Effects of dietary conjugated linoleic acid on fatty acid composition, lipid oxidation, color, and water-holding capacity of pork loin. Journal of Animal Science, 80, 108-112.

Jorgensen, K.A. \& Dyerberg, J. 1983. Platelets and atherosclerosis. Advances in Nutrition Research, 5, 57-6.

Kato, H. et al. 1973. Epidemiological studies of coronary heart disease and stroke of Japanese men living in Japan, Hawaii and California. American Journal Epidemiology, 97: 373.

Keys, A. 1970. Coronary heart disease in seven countries. Circulation, 41, 1

Kinsella, J.E., Lokesh, B. \& Stone, R.A. 1990. Dietary n-3 polyunsaturated fatty acids and amelioration of cardiovascular disease: possible mechanisms. American Journal Clinical Nutrition, 52, 1.

Madsen, H.L. \& Bertelsen, G. 1995. Spices as antioxidants. Trends Food Science and Technology, 6, 271-277.

Martino, R.C. \& Takahashi, N.S. 2001. A importância da adição de lipídios em rações para aqüicultura. Revista Óleos \& Grãos, São Caetano do Sul, 58, 32-37

Mathiesen, C.F. 2003. Conjugatedlinoleicacid in a slaughterpig diet. Animal performance, carcass quality traits and sensory quality. M.Sc. thesis, The Royal Veterinary and Agricultural University.

Matthews K.R. et al. 2000. Effect of whole linseed (Linumusitatissimum) in the diet of finishing pigs on growth performance and on the quality and fatty acid composition of various tissues.Brazilian Journal of Nutrition. $83,637-43$

Mersmann, H.J. 2002. Mechanisms for conjugated linoleic acid-mediated reduction in fat deposition. Journal of Animal Science, v.80, p.126-134.

Mcguire, M.A. \& Mcguire, M.K. 1999. Conjugated linoleic acid (CLA): a ruminant fatty acid with beneficial effects on human health. Proceedings of the American Society of Animal Science, 1-8

Myers, R.O. et al. 1992. Performance and carcass characteristics of swine when fed diets containing canola oil and added copper to alter the unsaturated:saturated ratio of pork fat. Journal of Animal Science, 70, 14171423.

Ostrowska, E., Muralitharan, M., Cross, R.F. et al. 1999. Dietary conjugated linoleic acids increase lean tissue and decrease fat deposition in growing pigs. Journal of Nutrition, 129, 2037-2042.

Pariza, M.W., Park, Y., Cook, M.E. 2001. The biologically active isomers of conjugated linoleic acid (Review). Progress in Lipid Research, 40, 283-298.

Park, Y., Albright, K., Liu, W.et al. 1997. Effect of conjugated linoleic acid on body composition in mice. LipidsResearch, 32, 853-858.

Pedroso, J.F. 2001. Óleos e gorduras na alimentação animal. In: Simpósio sobre ingredientes na alimentação animal, 2001, Campinas. Anais... Campinas, 199-218.

Petrón, M.J. 2002. Estudio de la fracción lipídica intramuscular en diferentes tipos de jamón Ibérico. $\mathrm{PhD}$ Thesis, Universidad de Extremadura.

Riley, A. et al. 2000. Animal Science. 71, 483500.

Rodriguez, C., Béjar, F., Rodrigáñez, J., et al. 1993. Componentes de varianza, heterosis y depresión consanguínea en el tamaño de 
camada de cerdos Ibéricos. Investigación Agraria Producción y Sanidad Animales, 8, 45-53.

Ruiz, J., Ventanas, J., Cava, R., Andres, A.I. et al. 2000. Texture and appearance of dry-cured ham as affected by fat content and fatty acid composition. Food Research International, 33, 91-95.

Sandstrom, B. et al. 2000. British Journal of Nutrition. 84, 143-150.

Scollan, N.D. et al. 2001. British Journal of Nutrition. 85, 115-124.

Sheard, P.R. et al. 2000. Shelf life and quality of pork and pork products with a raised n-3 PUFA. Meat Science. 55, 213-221.

Simopoulos, A.P. 1999a. Symposium: role of poultry products in enriching the human diet with N-3 PUFA: human requirement for N-3 polyunsaturated fatty acids. Poultry Science, 79, 961-970

Sinclair, A.J. 1993. Dietary dat and cardiovascular disease: the significance of recent developments for the food industry. Food Australia, 45, 226.

Stewart, J.W. et al. 2001. American Journal of Clinical Nutrition, 74, 179-87.

Tejeda, J.F., García, C., Muriel, E. et al. 2002. Muscle lipid composition of Iberian pig meat as related to genetic line. In 48th international congress of meat science and technology, 2, 734, Rome (Italy).

Tischendorf, F., Schöne, F.,Kirchheim, U. et al. 2002. Infuence of a conjugated linoleic acid mixture on growth, organ weights, carcass traits and meat quality in growing pigs. Journal of Animal Physiology and Animal Nutrition, 86, 117-128.

Tuley, L. 1995. Functional Foods - the technical issues. Food Manufacture, 70, 30-32.

Warnants, N. et al. 2001. Pig News and Information. 22, 107-113.

Wood, J.D. et al. 2003. Effects of fatty acids on meat quality: a review. Meat Science, 66, 2132.

Wood, J.D., 2004. Nute, G.R., Richardson, R.I., et al. Effects of breed, diet and muscle on fat deposition and eating quality in pigs. Meat Science, 67, 651-667.

\section{Recebido em Novembro 20, 2014}

Aceito em Maio 26, 2015

License information: This is an open-access article distributed under the terms of the Creative Commons Attribution License, which permits unrestricted use, distribution, and reproduction in any medium, provided the original work is properly cited. 